Research Article

\title{
Forensic Study on Sex Identification Using Radiographic Morphometric Evaluation of Frontal Sinus
}

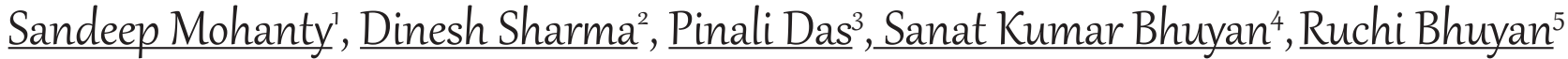 \\ ${ }^{1}$ MDS Consultant, ${ }^{2}$ Biostatistician, Jaiprakash Hospital and Research Center, Rourkela. \\ ${ }^{3} \mathrm{MDS}$, Oral Medicine and Radiology. \\ ${ }^{4} \mathrm{HOD}$, Oral Medicine and Radiology, Institute of Dental Science, Sum Hospital, Bhubaneswar. \\ ${ }^{5}$ Professor, Oral and Maxillofacial Pathology, Institute of Dental Science, Sum Hospital, Bhubaneswar. \\ DOI: https://doi.org/10.24321/2455.9199.201903
}

I $\mathbf{N}$ F $\mathbf{O}$

\section{Corresponding Author:}

Dinesh Sharma, Jaiprakash Hospital and Research

Center, Rourkela.

E-mail Id:

vashistdin@gmail.com

Orcid Id:

https://orcid.org/0000-0001-5980-4810

How to cite this article:

Mohanty S, Sharma D, Das P et al. Forensic Study on Sex Identification Using Radiographic Morphometric Evaluation of Frontal Sinus. Int J HealthCare Edu \& Med Inform 2019; 6(1): 6-9.

Date of Submission: 2019-07-15

Date of Acceptance: 2019-08-05

\section{$\begin{array}{llllllll}\mathbf{A} & \mathbf{B} & \mathbf{S} & \mathbf{T} & \mathbf{R} & \mathbf{A} & \mathbf{C} & \mathbf{T}\end{array}$}

In modern life many disasters, accidents, natural calamities occur \& identification of living or dead persons in such incidents are tough task since the field of forensic come into existance to deal with identification of a person for medico legal purpose.

Aim: To determining the gender of individuals by mathematical method using measurement of the frontal sinus through para nasal sinuses radiograph.

Material and Method: The study group consist of about 48 person both male and female are included. Digital Para nasal sinuses radiograph will be taken using standard technique for the evaluation of frontal sinus. Radiographic digital images will be imported and later area (height $\times$ width $\times$ area) of the frontal sinus will be evaluated.

Conclusion: The accuracy obtained in this study may be due to individual variation of frontal sinus is too great to attempt sex determination from this structure.

Keywords: Frontal Sinus, Personal Identification, Yoshino's Classification

\section{Introduction}

In modern era, many disasters, accidents, natural calamities often occurs and identification of living or dead person in such incidents is a tough task since the field of forensics came into existence to deal with identification of a person for medico legal purpose. ${ }^{1}$ Forensic medicine involves the role of radiological identifications predominantly when comparative DNA samples and fingerprints are absent. For this purpose, the ante-mortem radiographs, usually done for clinical reasons are compared with post-mortem radiographs taken exclusively for the identification of definite, individualized structures. ${ }^{2}$ Dental identification has been regarded as one of the primary identifiers. The best-preserved part of skeleton after death is the hard tissue and thus for forensic purpose the skull is sometimes the most valuable part. The radiographs that can be taken to establish identity of gender from a defleshed skull plays a predominant role such as lateral cephalograms and posteroanterior views. ${ }^{3}$ 
The two most important features depicted morphologically on the radiographs which must meet the requirements to be of forensic identification value: Initially, the feature has to be distinctive to the individual; secondly, stability with time in spite of the ongoing life processes. The uniqueness of frontal sinus in every individual plays a substantial role in forensics for gender determination because of its asymmetrical shape and its individual characteristics, like fingerprints. ${ }^{2}$ The present study was assessed to evaluate the gender of person through frontal sinus using Paranasal Sinus (PNS) view.

\section{Materials and Methods}

This retrospective radiological comparative study was conducted on panoramic radiographs for 48 subjects (24 males and 24 females) from Bhubaneswar, Odisha region, in the age group of 20 to 60 years in a period of 6 months. ${ }^{3}$ The subjects were considered in this study based on some inclusion and exclusion criteria. Before starting the study, ethical clearance was achieved from the ethical committee of the institution. PNS views required for study were obtained from the Department of Oral Medicine and Radiology, Institute of Dental Sciences, Bhubaneswar. PNS digital radiograph was taken through GE Haulun Systems Co. Ltd, Xiamen, china, ${ }^{5}$ Manual Collimator Model No. (5189248) x-rays. The data was measured through Image work CR 13.01 software. The date was obtained by doing proper clinical evaluation and radiographic examination of patients who have visited sum hospital and were advised for pns view were included in the study. All patient gave informed consent to participate in this study.

Height, width and also the total area of the left and right frontal sinus was measured through software (GE Haulun Systems Co. Ltd, Xiamen, china). The baseline for every measurement were considered from the part of frontal sinus projected above the superior border of the orbit. ${ }^{1}$ The width on each side of the sinus was quantified by the frontal sinus septum separating the left and the right side of the sinus. The calculation of the width of the frontal sinus bilaterally was done from the maximum distance between the medial and lateral lines. Further, calculating the height of the frontal sinus in both right and left side, the maximum distance between the base and upper lines of the sinus was considered. ${ }^{2}$ the study subjects were considered based some inclusion and exclusion criteria

\section{Inclusion Criteria ${ }^{4}$}

- All dentate patient (48 patients, 24 males \& 24 females)

- Clear PNS radiograph with visible structure and measurements were included in this study.

- Age group between 15 to 70 were selected.

- $\quad$ Age group was further divided into 5 sub age group.

- Retrospective study of individuals.

- All the measurement are measured in centimetre.

\section{Exclusion Criteria}

- No systematic bone disease radiograph are included.

\section{Statistical Analysis}

The descriptive analysis and logistic regression analysis (LRA) were performed using the SPSS version 20 (SPSS Inc., IL, USA).

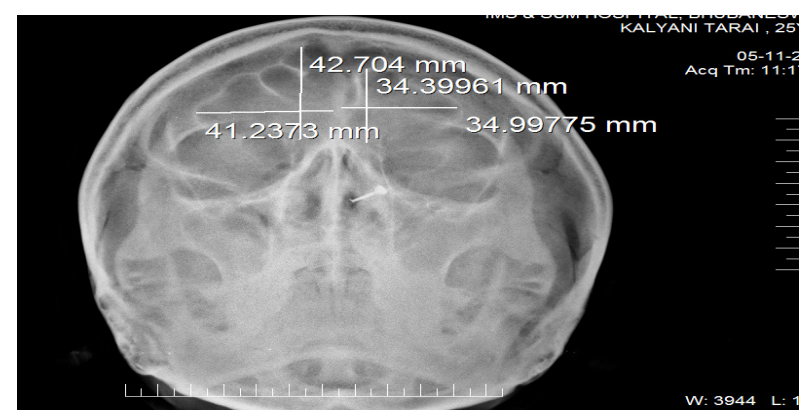

Figure I.PA view of skull with measurements of frontal sinus

Table I.Mean distribution of width, length and area of frontal sinus of different age group of males and females

\begin{tabular}{|c|c|c|c|c|c|c|c|}
\hline Gender & Age group & R -width & R-length & R-area & L-width & L-length & L-area \\
\hline Male & $15-24$ & 3.16 & 3.04 & 9.72 & 2.66 & 2.50 & 8.32 \\
\hline Female & $15-24$ & 2.08 & 2.125 & 4.6 & 3.08 & 2.9 & 8.8 \\
\hline Male & $25-34$ & 2.38 & 2.48 & 6.35 & 2.92 & 2.83 & 8.28 \\
\hline Female & $25-34$ & 3.4 & 3.34 & 11.66 & 3.55 & 3.19 & 11.35 \\
\hline Male & $35-44$ & 2.91 & 2.86 & 8.51 & 3.5 & 3 & 10.54 \\
\hline Female & $35-44$ & 2.1 & 1.85 & 3.85 & 2.55 & 2.35 & 6.25 \\
\hline Male & $45-54$ & 3.3 & 3.87 & 12.97 & 2.83 & 3.83 & 10.63 \\
\hline Female & $45-54$ & 3.45 & 3.14 & 10.4 & 3.56 & 3.3 & 12.21 \\
\hline Male & Above 55 & 3.58 & 3.28 & 11.73 & 3.33 & 3 & 9.9 \\
\hline Female & Above 55 & 3.35 & 3.45 & 11.5 & 3.65 & 3.7 & 13.45 \\
\hline
\end{tabular}


Table 2. Measurements of association between estimated probabilities and observed response

\begin{tabular}{|c|c|c|c|c|c|c|}
\hline Parameters & $\begin{array}{c}\text { Logistic regression } \\
\text { Y=A+BX }\end{array}$ & $\begin{array}{c}\text { p-value } \\
\text { for B }\end{array}$ & $\begin{array}{c}\text { 2 log } \\
\text { likelihood }\end{array}$ & $\begin{array}{c}\mathbf{X}^{2} \text { for model } \\
\text { FIT }\end{array}$ & p-value for Y & $\begin{array}{c}\text { \% of overall corrected } \\
\text { classification }\end{array}$ \\
\hline RT height & $\mathrm{Y}=1.694+0.914 \mathrm{X}$ & $0.006(\mathrm{~S})$ & 185.186 & 7.888 & $0.005(\mathrm{~S})$ & 57.57 \\
\hline LT height & $\mathrm{Y}=1.451+0.789 \mathrm{X}$ & $0.012(\mathrm{~S})$ & 187.489 & 7.580 & $0.007(\mathrm{~S})$ & 56.14 \\
\hline RT width & $\mathrm{Y}=1.345+0.631 \mathrm{X}$ & $0.025(\mathrm{~S})$ & 189.078 & 4.911 & $0.024(\mathrm{~S})$ & 61.00 \\
\hline LT width & $\mathrm{Y}=1.134+0.516 \mathrm{X}$ & 0.007 & 189.187 & 4.765 & 0.07 & 62.81 \\
\hline RT area & $\mathrm{Y}=1.396+0.565 X$ & $0.001(\mathrm{~S})$ & 180.510 & 11.555 & $0.002(\mathrm{~S})$ & 62.29 \\
\hline LT area & $\mathrm{Y}=1.103+0.35 \mathrm{X}$ & $0.004(\mathrm{~S})$ & 183.551 & 13.065 & $0.004(\mathrm{~S})$ & 64.44 \\
\hline
\end{tabular}

$\mathrm{P}<0.05$ Significant $(\mathrm{S}), \mathrm{P}>0.05 ; \mathrm{NS}=$ Non significant, $\mathrm{x}$ =Variable, $\mathrm{RT} H \mathrm{HT}=$ Right height, $\mathrm{LT} H \mathrm{HT}=$ Left height, $\mathrm{RT}$ WT = Right width, LT WD = Left width, RT AR = Right area and $L T A R=$ Left area.

\section{Result}

Table 1, shows the detail mean distribution of width, length and area of different groups. (males age 15-63 and females age 15-64). When the age increases there is increase in area of the left sinus as compared to right sinus in case of males and females. In comparing the width of the sinuses in males both the sides increase simultaneously as compared to females in which there is increase in only middle age. As compared males have larger frontal sinus than females. Mean measurement of left side frontal sinus was greater than the right side in both males and females. After applying logistic regression analysis values obtained for $\mathrm{RH}$ height, $\mathrm{LH}$ height, $\mathrm{RH}$ area and $\mathrm{LH}$ area variables came to be statistically significant. Accuracy rate in classification of males and females varies from $56.14 \%$ to $64.29 \%$. Accuracy values obtained for all the variables is of average level while left area (64.44\%) shows strong indications of the frontal sinus in determination of the gender. We obtained a formula $(y=$ $a+b x)$, with a constant (a) which is -0.749 , b coefficient is different for each variable which is mentioned as b1, b2, b3, b4, b5 and b6. Non-significant results are obtained for $p$ value of overall logistic regression analysis. We obtained an overall accuracy of $69.9 \%$ by regression analysis.
$\mathrm{P}<0.05$ Significant $(\mathrm{S}), \mathrm{P}>0.05 ; \mathrm{NS}=$ Non significant, $\mathrm{x}=$ Variable, RT HT = Right height, LT HT = Left height, RT WT = Right width, LT WD = Left width, RT AR = Right area and $\mathrm{LT} A R=$ Left area.

\section{Discussion}

In worst situations like mass disasters where human skeletons are damaged in victims who are trapped or burned, a necessity has risen to determine gender using frontal sinus as a useful means in forensic medicine. The radiographic images of frontal sinus in Para Nasal Sinuses (PNS) view gives the experts the chance to examine it alongside the bones, thus aiding in sex determination. The frontal sinus can sustain high temperature, hence is preserved in burned corpses after mass disasters such as air crashes. The radiological evidence of the frontal sinus is seen at the age of five or six and they completely develop by the 20 years of age. ${ }^{2}$

It was also inferred from the results that frontal sinus pneumatization becomes more with age and has specific variability. In this study mean measurement of left side frontal sinus was greater than the right side in both males and females (Table 1), which agrees to the study was done by Belaldavar $\mathrm{C}$ et al., Yoshino $\mathrm{M}$ et al. ${ }^{3,4}$ But, in a study outlined by Belaldavar $\mathrm{C}$ et al. according to which the mean measurement of right-side frontal sinus was greater than the left side irrespective of the gender. The tendency of the

Table 3.Regression co-efficient of all variables

\begin{tabular}{|c|c|c|c|c|c|c|}
\hline Variable & $\begin{array}{c}\text { Regression } \\
\text { coefficient B }\end{array}$ & $\mathbf{p}$-value for B & $\begin{array}{c}-\mathbf{2} \text { log } \\
\text { likelihood }\end{array}$ & $\begin{array}{c}\mathbf{X}^{2} \text { for } \\
\text { model fit }\end{array}$ & $\begin{array}{c}\text { P-value } \\
\text { for } \mathbf{Y}\end{array}$ & $\begin{array}{c}\text { \% of overall corrected } \\
\text { classification }\end{array}$ \\
\hline RT HT (B1) & -0.114 & 0.857 (NS) & & & & \\
\hline LT HT (B2) & -0.093 & 0.870 (NS) & & & & \\
\hline RT WD (B3) & -0.310 & 0.598 (NS) & 181.615 & 14.555 & $0.045(\mathrm{~S})$ & 69.9 \\
\hline LT WD (B4) & -0.289 & 0.488 (NS) & & & & \\
\hline RT AR (B5) & 0.591 & 0.056 (NS) & & & & \\
\hline LT AR (B6) & 0.350 & 0.136 (NS) & & & & \\
\hline Constant & -0.756 & 0.412 (NS) & & & & \\
\hline
\end{tabular}


left side to be greater than the right was seen in agreement with the results from other studies..$^{6-8}$ This discrepancy in the sides can be attributed to their independent development. ${ }^{9}$ We also found the morphology of each frontal sinus of both males and females were different and were also asymmetrical. In comparing the width of the sinuses in males both the sides increase simultaneously as compared to females in which there is increase in middle age which is statistically insignificant. As compared males have larger left frontal sinus than females. Logistic regression analysis to determine the accuracy in sex prediction which shows the accuracy rate in classification of males and females varied from $56.14 \%$ to $64.44 \%$ (Table 2).

The accuracy of Right area (62.29\%) and left width (64.44\%) were established as better regressor (Table 2). The predictive value obtained when all variables were used was found to be $69.9 \%$ (Table 3). In a similar study by Nortjie CJ, Harris AM and Mohan NV et al. using PA and PNS view for correct sex determination found an accuracy of $79.7 \%$ and $67.9 \%$ respectively. ${ }^{1,5}$ They also found left area to be better suited for determination of sex. Uthman AT et al. ${ }^{10}$ on Iraqi population using CT scan for evaluation of frontal sinus and skull measurement in sex determination, found an accuracy of $76.9 \%$ in determining the sex by frontal sinus using discriminant functional analysis. However, when they combined skull measurement and frontal sinus measurement, they obtained an accuracy of $85.9 \%$ in sex identification. Kiran CS et al. ${ }^{11}$ framed that the dimorphic features of frontal sinus in both men and women, there was significant differences observed in the frontal sinus parameters. We developed the regression equation which can be used to determine sex using frontal sinus among Indian population. The accuracy obtained was less in this study may be due to variation of frontal sinus in the individuals was a difficult attempt for sex determination regarding its structure.

\section{Conclusion}

The results show that left side frontal sinus of males is greater than females. The reduced accuracy obtained in this study may be due to individual's dissimilarity of frontal sinus in its pattern and structure to attempt sex determination. In every population, the configuration of frontal sinus is also affected by genetic and environmental factors. However larger sample size and statistical analysis between different age groups can make this study more significant.

\section{Limitation of the Study}

Only determination of gender is done, determination of age, personal identification and the consideration of various ethnic groups and the undertaking of a larger samples size would have given more significant value.

\section{Conflict of Interest: None}

\section{References}

1. Mohan NV, Kumar JS, Kumar SC. Morphometric evaluation of frontal sinus in relation to gender - a forensic study. University J Dent Sci 2015; 1(2): 7-11.

2. Soman BA, Sujatha GP, Lingappa A. Morphometric evaluation of the frontal sinus in relation to age and gender in subjects residing in Davangere, Karnataka. J Forensic Dent Sci 2016; 8(1): 57.

3. Yoshino M, Miyasaka $\mathrm{S}$, Sato $\mathrm{H}$ et al. Classification system of frontal sinus patterns by radiography. Its application to identification of unknown skeletal remains. Forensic Sci Int 1987; 34: 289-99.

4. Belaldavar C, Kotrashetti VS, Hallikerimath SR et al. Assessment of frontal sinus dimensions to determine sexual dimorphism among Indian adults. J Forensic Dental Sci 2014; 6(1): 25-28.

5. Nortje CJ, Harris AM. Maxillo-facial radiology in forensic dentistry: a review. J Forensic Odontostomatol 1986; 4(1): 29-38.

6. RubiraBullen IR, Rubira CM, Sarmento VA et al. Frontal sinus size on facial plain radiographs. J Morphol Sci 2010; 27: 7781.

7. Pondé JM, Metzger P, Amaral G et al. Anatomic variations of the frontal sinus. Minim Invasive Neurosurg 2003; 46: 2932.

8. Tatlisumak E, Ovali GY, Asirdizer M et al. CT study on morphometry of frontal sinus. Clin Anat 2008; 21: 28793.

9. Nambiar P, Naidu MD, Subramaniam K. Anatomical variability of the frontal sinuses and their application in forensic identification. Clin Anat 1999; 12: 16-19.

10. Uthman AT, Al-Rawi NH, Al-Naaimi AS et al. Evaluation of frontal sinus and skull measurements using spiral CT scanning: an aid in unknown person identification. Forensic Sci Int 2010; 197(1-3): 124.e1-7.

11. Kiran CS, Ramaswamy P. Frontal sinus index - A new tool for sex determination. Forensic Radiol Imag 2014, 2(2): 77-79.

\section{Funding: None}

